\title{
Large-scale collection and annotation of full-length enriched cDNAs from a model halophyte, Thellungiella halophila
} Teruaki Taji ${ }^{\dagger 1,2}$, Tetsuya Sakurai ${ }^{\dagger 3}$, Keiichi Mochida ${ }^{3}$, Atsushi Ishiwata ${ }^{3}$, Atsushi Kurotani ${ }^{3}$, Yasushi Totoki ${ }^{4,5}$, Atsushi Toyoda ${ }^{4}$, Yoshiyuki Sakaki ${ }^{4}$, Motoaki Seki ${ }^{3}$, Hirokazu Ono ${ }^{1}$, Yoichi Sakata1 ${ }^{1}$, Shigeo Tanaka ${ }^{1}$ and Kazuo Shinozaki*2,3

\author{
Address: ${ }^{1}$ Faculty of Applied Bioscience, Tokyo University of Agriculture, 1-1-1 Sakuragaoka, Setagaya-ku, Tokyo 156-8502, Japan, ${ }^{2}$ Laboratory of \\ Plant Molecular Biology, RIKEN Tsukuba Institute, 3-1-1 Koyadai, Tsukuba, Ibaraki 305-0074, Japan, ${ }^{3}$ RIKEN Plant Science Center, 1-7-22 \\ Suehiro-cho, Tsurumi-ku, Yokohama, Kanagawa 230-0045, Japan, ${ }^{4}$ RIKEN Genomic Sciences Center, 1-7-22 Suehiro-cho, Tsurumi-ku, Yokohama, \\ Kanagawa 230-0045, Japan and ${ }^{5}$ MetaSystems Research Team, RIKEN Advanced Science Institute, Yokohama, 230-0045, Japan \\ Email: Teruaki Taji - t3teruak@nodai.ac.jp; Tetsuya Sakurai - stetsuya@psc.riken.jp; Keiichi Mochida - mochida@psc.riken.jp; \\ Atsushi Ishiwata - aishiwata@psc.riken.jp; Atsushi Kurotani - kurotani@psc.riken.jp; Yasushi Totoki - totoki@gsc.riken.jp; \\ Atsushi Toyoda - toyoda@gsc.riken.jp; Yoshiyuki Sakaki - sakaki@gsc.riken.jp; Motoaki Seki - mseki@psc.riken.jp; \\ Hirokazu Ono-55070009@ nodai.ac.jp; Yoichi Sakata - sakata@nodai.ac.jp; Shigeo Tanaka - stanaka@nodai.ac.jp; \\ Kazuo Shinozaki* - sinozaki@rtc.riken.jp \\ * Corresponding author †Equal contributors
}

Published: 12 November 2008

BMC Plant Biology 2008, 8:1/5 doi:10.1 |86/147|-2229-8-II5
Received: 25 July 2008

Accepted: 12 November 2008

This article is available from: http://www.biomedcentral.com//47I-2229/8/I I5

(C) 2008 Taji et al; licensee BioMed Central Ltd.

This is an Open Access article distributed under the terms of the Creative Commons Attribution License (http://creativecommons.org/licenses/by/2.0), which permits unrestricted use, distribution, and reproduction in any medium, provided the original work is properly cited.

\begin{abstract}
Background: Thellungiella halophila (also known as Thellungiella salsuginea) is a model halophyte with a small plant size, short life cycle, and small genome. It easily undergoes genetic transformation by the floral dipping method used with its close relative, Arabidopsis thaliana. Thellungiella genes exhibit high sequence identity (approximately $90 \%$ at the cDNA level) with Arabidopsis genes. Furthermore, Thellungiella not only shows tolerance to extreme salinity stress, but also to chilling, freezing, and ozone stress, supporting the use of Thellungiella as a good genomic resource in studies of abiotic stress tolerance.

Results: We constructed a full-length enriched Thellungiella (Shan Dong ecotype) cDNA library from various tissues and whole plants subjected to environmental stresses, including high salinity, chilling, freezing, and abscisic acid treatment. We randomly selected about 20000 clones and sequenced them from both ends to obtain a total of 35 I7I sequences. CAP3 software was used to assemble the sequences and cluster them into 9569 nonredundant cDNA groups. We named these cDNAs "RTFL" (RIKEN Thellungiella Full-Length) cDNAs. Information on functional domains and Gene Ontology (GO) terms for the RTFL cDNAs were obtained using InterPro. The $\mathbf{8 2 8 9}$ genes assigned to InterPro IDs were classified according to the GO terms using Plant GO Slim. Categorical comparison between the whole Arabidopsis genome and Thellungiella genes showing low identity to Arabidopsis genes revealed that the population of Thellungiella transport genes is approximately I.5 times the size of the corresponding Arabidopsis genes. This suggests that these genes regulate a unique ion transportation system in Thellungiella.

Conclusion: As the number of Thellungiella halophila (Thellungiella salsuginea) expressed sequence tags (ESTs) was 9388 in July 2008, the number of ESTs has increased to approximately four times the original value as a result of this effort. Our sequences will thus contribute to correct future annotation of the Thellungiella genome sequence. The full-length enriched cDNA clones will enable the construction of overexpressing mutant plants by introduction of the cDNAs driven by a constitutive promoter, the complementation of Thellungiella mutants, and the determination of promoter regions in the Thellungiella genome.
\end{abstract}




\section{Background}

Thellungiella halophila (also known as Thellungiella salsuginea) is well known as a model halophyte for studying abiotic stress tolerance, as the plant exhibits extreme salt and freezing tolerance [1-9]. Thellungiella is closely related to Arabidopsis, and its genes share approximately 90\% identity to those of Arabidopsis $[1,10,11]$. Moreover, Thellungiella is characterized by good features from the perspective of genetic studies, such as small plant size, a short life cycle, a high seed number, and the ability to selfpollinate. Furthermore, as in Arabidopsis, transformation of Thellungiella plants can be accomplished by means of the floral dipping method. Since the sequence identities between Thellungiella and Arabidopsis are very high at the cDNA level, Arabidopsis cDNA microarrays or oligomicroarrays can be used for transcriptome analysis of Thellungiella plants. We previously compared expression levels of various genes between Thellungiella and Arabidopsis plants under normal or high-salinity conditions using an Arabidopsis cDNA microarray composed of 7,000 Arabidopsis genes. Interestingly, a large number of genes known to be inducible by abiotic and biotic stresses were highly expressed in Thellungiella under normal growth conditions [5]. The use of a 70-mer oligoarray with 25000 Arabidopsis genes revealed that Arabidopsis exhibited a global defense strategy required for bulk protein synthesis, whereas induced genes in Thellungiella were involved in protein folding, modification, and redistribution [2]. However, because of failed hybridization or a low hybridization rate between Arabidopsis DNAs and Thellungiella mRNAs, the data obtained from heterologous microarrays cannot provide an accurate evaluation of the expression levels. Recently, Thellungiella plants (Yukon ecotype) treated with drought, salinity, and freezing stresses were used to construct expressed sequence tag (EST) libraries with a total of 3628 unique genes [9]. A cDNA microarray was established with these cDNAs, and the transcriptional profiles of Thellungiella plants under various stress conditions were obtained [8].

Full-length cDNAs are useful genomic resources not only for genome annotation, but also for the identification of promoter regions, transgenic analyses, biochemical analyses, and determination of the three-dimensional structure of proteins [12]. Full-length enriched cDNA libraries from
Arabidopsis [13,14], rice [15], poplar [16,17], wheat [18], maize [19], humans [20], mice [21,22], and Drosophila [23-25] have contributed enormously to elucidating biological processes in these organisms.

In previous work, we reported the development of fulllength enriched Arabidopsis cDNA libraries from plants grown under different conditions $[13,26]$ using the biotinylated CAP trapper method with trehalose-thermoactivated reverse transcriptase [27-30]. A total of 155144 RIKEN Arabidopsis Full-Length (RAFL) clones were isolated and clustered into 14668 non-redundant cDNA groups [14]. Using the full-length cDNAs, we also created a microarray to analyze the expression profiles of Arabidopsis genes under various stress conditions or in various mutants and transgenic plants $[12,26]$. Using ectopic expression of full-length cDNAs, a novel gain-of-function system, termed the "FOX hunting system" (Full-length cDNA Over-eXpressing gene hunting system) was developed [31]. The Arabidopsis genome sequence and resources, including full-length cDNAs, also provide powerful tools for comparative genomics in furthering the understanding of the biology and evolution of other plant species $[2,5,10,32]$. In the present study, we constructed a full-length enriched cDNA library from whole Thellungiella plants and various tissues, in addition to cDNAs from seedlings subjected to high salinity, chilling, or freezing stress or to abscisic acid (ABA) treatment. We determined their DNA sequences from both the 5'- and the 3 '-ends to permit the functional annotation of the Thellungiella full-length cDNAs, and we discuss their predicted functions related to abiotic stress tolerance.

\section{Results and Discussion \\ Full-length enriched cDNA library construction and sequencing of $20000 \mathrm{cDNAs}$}

We used the biotinylated CAP trapper method [29] to construct a full-length cDNA library of Thellungiella halophila (Shandong ecotype) from whole plants as well as from various tissues, including leaves, roots, flowers, siliques, and mature seeds, of plants treated with high salinity, chilling, freezing stress, and ABA (Table 1). The $\lambda$ FLCIII vector [33], which accommodates cDNAs in a broad range of sizes and is useful for the high-efficiency cloning of long cDNA fragments, was used for the con-

Table I: Collection of RNA sample for constructing a Thellungiella full-length cDNA library

\begin{tabular}{lllll}
\hline Sample name & Condition & Time course & Condition & Tissues \\
\hline salt stress & $\mathrm{NaCl}, 250 \mathrm{mM}$ & $\mathrm{I}, 2,3,7$ and 14 day & agar medium & whole plants \\
cold stress & $4^{\circ} \mathrm{C}$ & $2,4,8$ and 24 hour & soil & rosette leaves \\
freezing stress & $-6^{\circ} \mathrm{C}$ & $\mathrm{I}, 2,4$ and 8 hour & soil & rosette leaves \\
$\mathrm{ABA}$ & $\mathrm{ABA} 50 \mu \mathrm{M}$ & $\mathrm{I}, 2,4$ and 8 hour & agar medium & whole plants \\
various tissues & normal condition & & soil & siliques, mature seeds
\end{tabular}


struction of the cDNA library. To reduce the frequency of representation of highly expressed mRNAs in the library, normalization procedures [29] were employed in the construction process. The 20000 recombinant clones were randomly selected and sequenced from both ends. We determined 18636 and 16535 sequences from the forward and reverse directions, respectively, and from among the 20000 clones we obtained the forward or reverse sequences of a total of 19429 clones (Table 2). A total of 35171 sequences have been deposited in the DDBJ public sequence database (accession numbers, BY800476 to BY835646). We have named these "RTFL" (RIKEN Thellungiella Full-Length) cDNAs.

Figure 1 shows the size distribution of the Thellungiella cDNA inserts from 1161 randomly selected clones. The average size was approximately $1.54 \mathrm{kbp}$. Our group previously determined 20683 full-read cDNA sequences from the RAFL (RIKEN Arabidopsis Full-Length) cDNA collection, and these sequences are available in the RARGE database [34]. The estimated average size of the RAFL cDNA inserts was $1.495 \mathrm{kbp}$ (Motoaki Seki et al., RIKEN Plant Science Center, unpublished results). The average size of the Thellungiella cDNA inserts was thus slightly longer than the average cDNA inserts from Arabidopsis libraries and similar to those in other plants; for example, the average rice and wheat cDNA lengths are both about $1.5 \mathrm{kbp}[10,18]$.

\section{Sequence assembly and the proportion of full-length cDNA clones in the library}

The 35171 sequences were assembled by using the CAP3 program [35] to evaluate the level of sequence redundancy. Assembling these sequences generated 7402 contigs and 6556 singletons, and the sequenced 20000 cDNAs were clustered into 9569 nonredundant scaffolds that represented distinct genes (Table 2). Figure 2 shows the degree of redundancy in the sequences from the cDNA library. The majority of the cDNAs (6024 cDNAs, $63 \%$ of the total), consisted of a single cDNA in a cluster, and only $5 \%$ contained more than six cDNAs in a cluster, indicating that the normalization procedures were successful.

The cDNA sequence data were submitted for the BLASTN search to compare with the green plants (Viridiplantae) mRNA databases in GenBank. Of the 19429 clones that we obtained as clean sequences, 18295 clones (94\%) showed $>80 \%$ identity, whereas the remaining clones $(6 \%)$ had no significant identity to any plant sequences in GenBank.

We examined the proportion of full-length cDNA clones in our library. We selected clones that (1) had sequences from both ends, and (2) showed an Expected Value $(E)<$ $1.0 \mathrm{e}^{-20}$ on the basis of a fastx search using forward sequences as queries against Arabidopsis proteins (TIGR v5, ATH1.pep, ftp://ftp.tigr.org/pub/data/a thaliana/ ath1/SEQUENCES/), with the correct direction of the reading frame. We considered clones to be full-length if they met the following criteria: (1) they contained the first methionine, and (2) the reverse sequence contained the polyA sequence. Consequently, we selected 12878 clones as calculation objects and classified 10880 (84.5\%) of these clones as full-length clones. This frequency is nearly identical to the reported values from the Arabidopsis [14], rice [15], and wheat [18] libraries.

\section{Functional annotation of RTFL CDNAs}

The 9569 nonredundant genes were submitted to InterPro [36] to obtain functional domain information. InterPro is an integrated resource for protein families, domains and functional sites that integrates the following protein signature databases: PROSITE, PRINTS, ProDom, Pfam, SMART, TIGRFAMs, PIRSF, SUPERFAMILY, Gene3D, and PANTHER. Protein matches in InterPro are pre-calculated by using InterProScan software, which combines the different protein signature recognition methods offered by the InterPro member databases into one resource and provides the corresponding InterPro accession numbers and Gene Ontology (GO) annotations [37]. A total of 8289 sequences were assigned to InterPro IDs and GO terms [see Additional file 1]. According to the obtained GO terms, the 8289 genes were remapped and classified by using Plant GO Slim (http://www.geneontology.org/ GO.slims.shtml; [38]).

Figures 3 and 4 show the categorization of Arabidopsis genes and the 8289 Thellungiella genes assigned to the GO terms. In most categories, we observed no obvious differences between the numbers of sequences from Arabidopsis and Thellungiella, including genes involved in biological processes, cellular components, and molecular

Table 2: Characteristics of full-length Thellungiella cDNA library

\begin{tabular}{ccccccc}
\hline $\begin{array}{c}\text { Source of } \\
\text { cDNA }\end{array}$ & Total no. clones & $\begin{array}{c}\text { No. forward } \\
\text { sequences }\end{array}$ & $\begin{array}{c}\text { No. reverse } \\
\text { sequences }\end{array}$ & $\begin{array}{c}\text { Total no. } \\
\text { sequences }\end{array}$ & $\begin{array}{c}\text { Total no. } \\
\text { singletons after } \\
\text { CAP3 analysis }\end{array}$ & $\begin{array}{c}\text { Total no. } \\
\text { contigs after } \\
\text { CAP3 analysis }\end{array}$ \\
\hline RTFLa & 19429 & 18636 & 16535 & 35171 & 6556 & 7402 \\
\hline
\end{tabular}

aRTFL, RIKEN Thellungiella halophila full-length cDNA 


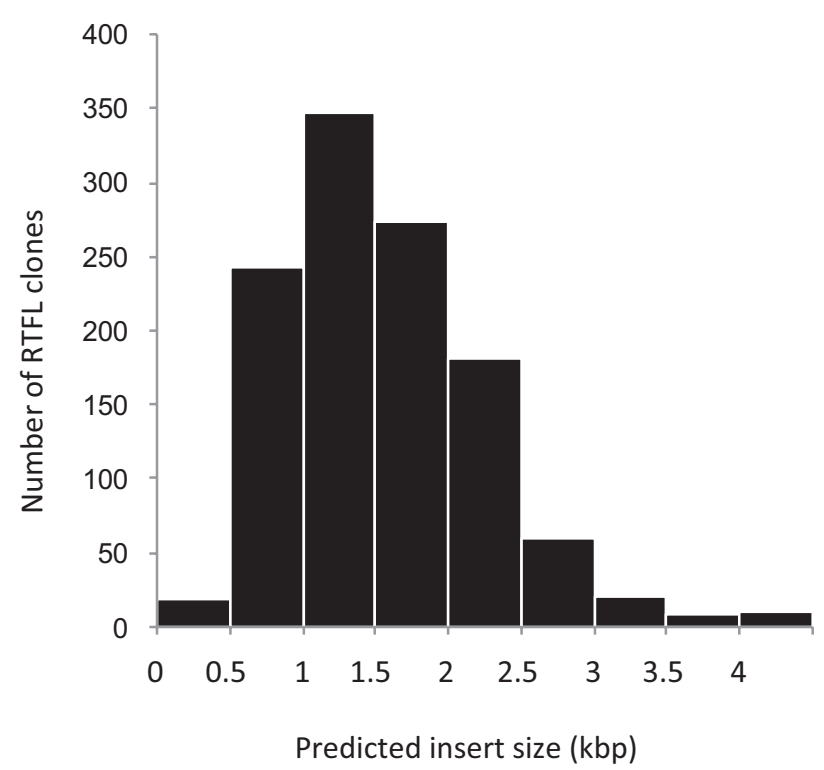

Figure I

Size distribution of the RTFL clones. The sequence lengths of the Thellungiella cDNA inserts were determined from a total of II6I clones by digestion with Sfil (in the cDNA cloning site) or PCR amplification using T3 and T7 primers.

function. Notably, the number of sequences classified as transcription genes under biological processes in Arabidopsis was approximately twice that in Thellungiella (Fig. 4). Furthermore, the number of Arabidopsis genes associated with the nucleus under cellular components was also much higher than that in Thellungiella (Fig. 3A). Although the total number of transcription factors is not clear in Thellungiella genome, there seems to be no significant difference in the proportion of transcription factor genes between Arabidopsis and Thellungiella genome. The population of cDNAs may reflects the levels of gene expression. Thus, the expression level of Thellungiella transcription factors may be lower than that of Arabidopsis. Arabidopsis responds strongly to abiotic and biotic stresses at the transcriptional level. In contrast, Thellungiella does not initiate immediate changes in transcription in response to abiotic stresses, and instead constitutively expresses a large number of genes that correspond to stress-inducible genes in Arabidopsis [5]. Thus, the difference between Arabidopsis and Thellungiella in their responses to various stimuli at the transcriptional level may reflect differences in the number of transcription-related genes between the organisms and may depend partly on the number of transcription factors.

\section{Features of Thellungiella-specific genes}

Most Thellungiella genes have a high sequence identity (approximately 90\% at the cDNA level) to Arabidopsis

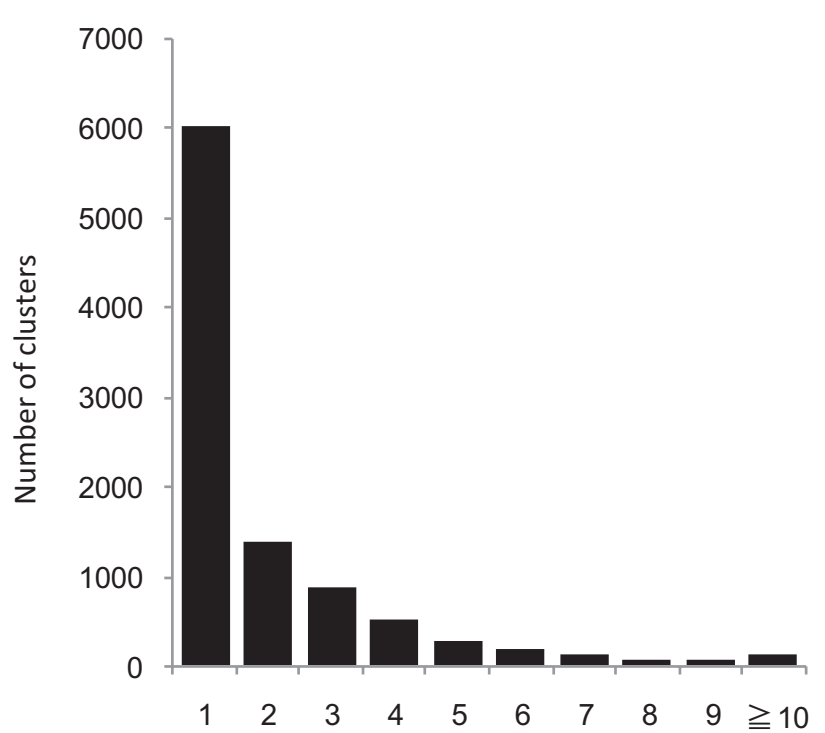

Number of cDNAs in a cluster

Figure 2

Sequence redundancy in the normalized cDNA library. A total of 35I7I sequences were assembled and divided into 9569 clusters. The graph represents the number of clones per assembled scaffold. Clusters containing a single cDNA accounted for $63 \%$ of the identified sequences, whereas clusters that contained more than six cDNAs accounted for only $5 \%$ of the total.

genes. Numerous studies of salt tolerance in Arabidopsis suggest that this plant contains most, if not all, the salttolerance related genes that might be found in halophytes[39]. The current hypothesis is that halophytes employ salt-tolerance mechanisms similar to those found in glycophytes, including Arabidopsis. However, subtle differences in this regulation result in large variations in salt tolerance between glycophytes and halophytes[11]. In addition, halophytes are hypothesized to exhibit specific salt-tolerance mechanisms resulting from the induction of halophyte-specific genes. We divided the 8298 genes into two groups on the basis of their sequence identities, using BLASTX searches against the Arabidopsis database. The group with high sequence identity to Arabidopsis genes ( $E$ value $\leq 1.0 e^{-50}$ ) included 7535 genes, and the group with low identity to Arabidopsis genes ( $E$ value $\left.>1.0 e^{-50}\right)$ included 763 genes. Previous studies revealed that a plasma membrane $\mathrm{Na}^{+} / \mathrm{H}^{+}$antiporter (SOS1), a vacuolar $\mathrm{Na}^{+} / \mathrm{H}^{+}$antiporter (NHX1), and a plasma membrane $\mathrm{Na}^{+}$ transporter (HKT1) are essential for the salt tolerance of Arabidopsis [40-42], and these mutants exhibit a salthypersensitive phenotype. In contrast, plants that overexpress SOS1 and NHX1 show higher salt tolerance than wild-type plants $[43,44]$. The co-ortholog Thellungiella genes belong to the first gene group, exhibiting high iden- 
A

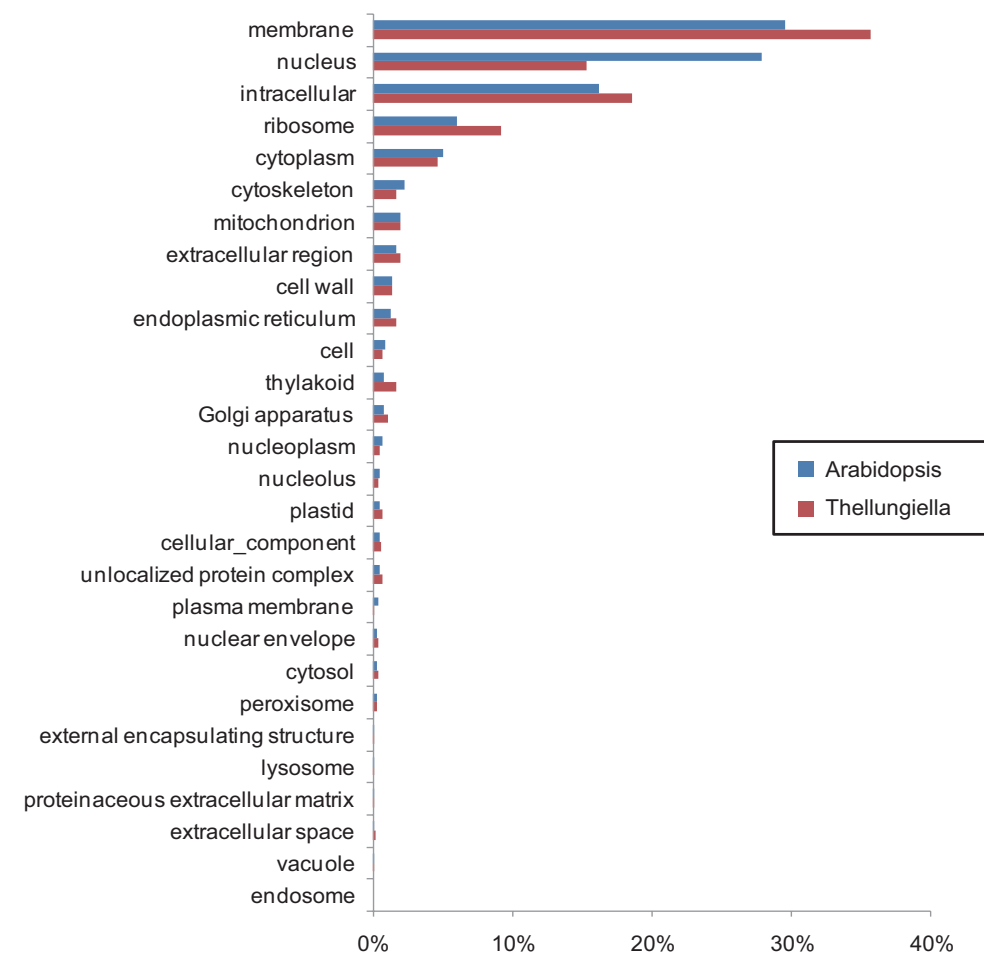

B

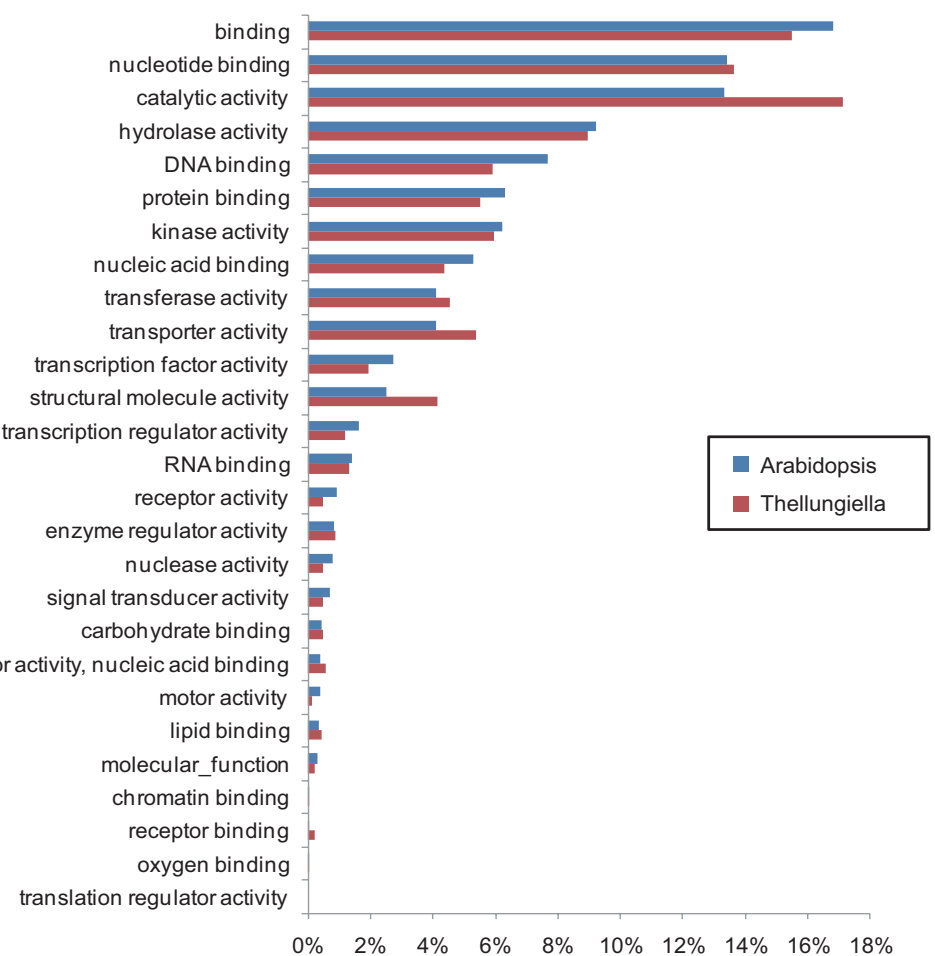

Figure 3

Comparison of the categories of Arabidopsis and nonredundant Thellungiella genes. The 28227 Arabidopsis genes and the 8298 nonredundant Thellungiella genes that were assigned InterPro IDs were classified according to the GO terms using Plant GO Slim http://www.geneontology.org/GO.slims.shtml into categories based on (A) cellular components and (B) molecular function. 


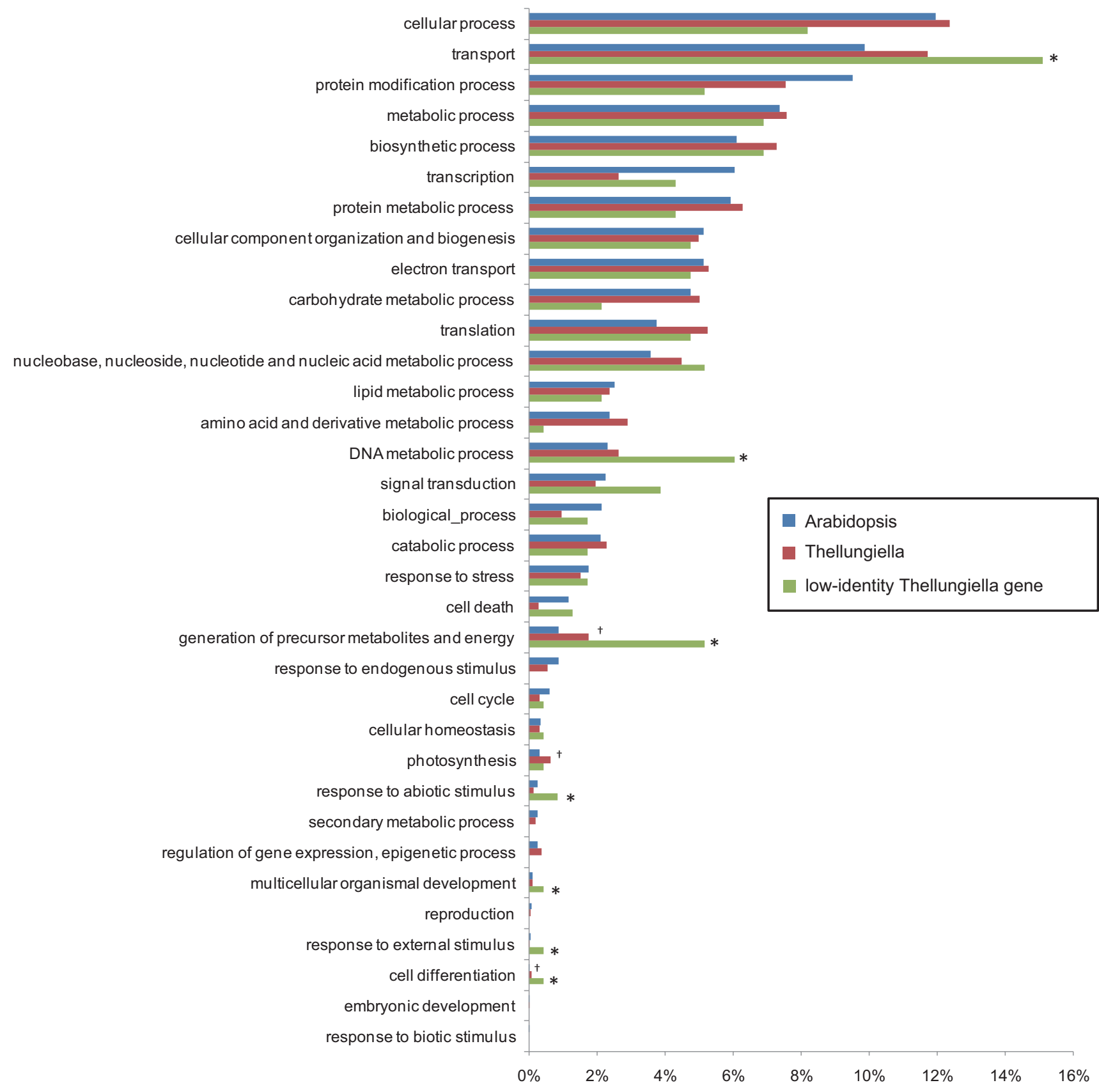

\section{Figure 4}

Biological process categories for Arabidopsis genes, nonredundant Thellungiella genes, and Thellungiella genes that showed low identity to Arabidopsis genes. The 28227 Arabidopsis genes, the 8298 nonredundant Thellungiella genes, and the 763 Thellungiella genes that showed low identity to Arabidopsis genes assigned to InterPro IDs were classified according to the GO terms using Plant GO Slim http://www.geneontology.org/GO.slims.shtml for biological processes. $\dagger$ indicates the categories in which the number of Thellungiella genes was more than 1.5 times the number of Arabidopsis genes. $*$ indicates categories in which the number of Thellungiella genes was more than I.5 times the number of Arabidopsis genes. The number of Thellungiella genes under the categories of transport, DNA metabolic process, generation of precursor metabolites and energy, response to abiotic stimulus, multicellular organismal development, response to external stimulus, and cell differentiation was more than I.5 times that in Arabidopsis. 
tity to Arabidopsis genes. This suggests that some salt-tolerance mechanisms are common to both glycophytes and halophytes.

We compared the categorization of the whole Arabidopsis genome with the categories of the 763 Thellungiella genes that exhibited low identity to Arabidopsis genes (Fig. 4). Of the genes involved in biological processes, the number of genes in the categories for transport, DNA metabolic process, generation of precursor metabolites and energy, response to abiotic stimulus, multicellular organismal development, response to external stimulus, and cell differentiation in Thellungiella were more than 1.5 times the number in Arabidopsis (Fig. 4). Moreover, in regards to molecular function, the proportion of genes involved in transporter activity in Thellungiella was also higher than in Arabidopsis. Less $\mathrm{NaCl}$ accumulates in Thellungiella plants than in Arabidopsis under similar salinity conditions, suggesting that Thellungiella has a superior system for suppressing $\mathrm{Na}^{+}$influx or for excreting $\mathrm{Na}^{+}$[5]. Electrophysiological analysis indicates that Thellungiella also exhibits high potassium/sodium selectivity, implying that Thellungiella has specific ion channel features that lead to superior homeostasis with respect to sodium and potassium [7]. Arabidopsis that overexpresses a plasma membrane $\mathrm{Na}^{+} / \mathrm{H}^{+}$antiporter gene, SOS1, shows salinity tolerance and represses its sodium uptake compared with that of wild-type plants [44]. Likewise, the expression level of SOS1 in Thellungiella is higher than in Arabidopsis $[5,45]$. Although SOS1 overexpression suggests a contribution of this gene to the salt tolerance of Thellungiella, the large proportion of transport genes may imply that Thellungiella has a distinct ion transportation system regulated by these specific genes.

\section{Salt tolerance system using Thellungiella-specific transporter genes}

Table 3 [see Additional file 2] lists the Thellungiella genes with low identity $\left(E\right.$ value $\left.>1.0 e^{-50}\right)$ to the Arabidopsis genes classified under transporter genes. Several transporters, including chloride channels and P-type $\mathrm{H}^{+}$-ATPase, play important roles in the salt tolerance of plants. Homeostasis of $\mathrm{Na}^{+}$and $\mathrm{Cl}^{-}$is an important mechanism to reduce $\mathrm{NaCl}$ stress in higher plants. Chloride channels (CLCs) are a group of voltage-gated $\mathrm{Cl}^{-}$channels originally identified in animals [46]; they have diverse cellular functions such as stabilizing cell membrane potential and regulating cell volume and transcellular chloride transport [47]. Recently, a chloride channel gene, GmCLC1, was cloned from soybeans [48]. Transgenic tobacco BY-2 cells expressing GmCLC1 were able to drain $\mathrm{Cl}^{-}$more efficiently from vacuoles than was the case in untransformed BY-2 cells, and the transgenics showed a higher $\mathrm{NaCl}$ tolerance [48]. The plant cell membrane is energized by an electrochemical gradient produced by P-type $\mathrm{H}^{+}$-ATPase (proton pump). These pumps are encoded by at least 12 genes in Arabidopsis. One of the Arabidopsis P-type $\mathrm{H}^{+}$-ATPase genes, AHA4, was expressed most strongly in the root endodermis [49]. The aha4 mutant plants exhibited a clear growth reduction under a mild stress of $75 \mathrm{mM} \mathrm{NaCl}$ compared with wild-type plants, and the ratio of $\mathrm{Na}^{+}$to $\mathrm{K}^{+}$ in the aha4 mutants increased to between four and five times the values in wild-type plants. These results suggest that the aha4 mutants were compromised in their ability to exclude $\mathrm{Na}^{+}$under salinity stress [49]. P-type $\mathrm{H}^{+}$ ATPases were also found in a halotolerant cyanobacterium, Aphanothece halophytica, and a marine alga, Tetraselmis viridis [50,51]. Aphanothece halophytica grows under a wide range of salinity conditions (from 0.25 to $3.0 \mathrm{M} \mathrm{NaCl}$ ), and $\mathrm{Na}^{+} / \mathrm{H}^{+}$antiporters in A. halophytica play a crucial role in $\mathrm{Na}^{+}$efflux to provide enhanced salt tolerance. Since the efflux of $\mathrm{Na}^{+}$mediated by $\mathrm{Na}^{+} / \mathrm{H}^{+}$antiporters utilizes protons as the motive force provided by a primary proton pump, $\mathrm{H}^{+}$-ATPase, the P-type $\mathrm{H}^{+}$-ATPase is thought to contribute to the salt tolerance of this species [52]. On the other hand, vacuolar ATPase (V-ATPase) is the major proton pump that establishes and maintains an electrochemical proton gradient across the tonoplast. Expression of several V-ATPase subunits or an increase in V-ATPase activity induced by salt stress has been observed in a number of glycophytic species [53], suggesting that increased V-ATPase levels or activity are required to drive $\mathrm{Na}^{+}$sequestration under salt stress. Recently, the $\mathrm{V}$ ATPase-deficient det3 Arabidopsis mutant was shown to be extremely salt sensitive. Moreover, SOS2, a protein kinase that phosphorylates SOS1, interacted directly with the V-ATPase regulatory subunits B1 and B2 [54]. These studies indicate that $\mathrm{V}$-ATPase activity plays a key role in salt tolerance. Although most Thellungiella genes show approximately 90\% identity with Arabidopsis genes, the Thellungiella genes encoding transporters appear to be remarkably different from their Arabidopsis co-orthologs. Whether the sequence diversities among these genes are the source of the large differences in salt tolerance between Thellungiella and Arabidopsis is a topic of great interest.

\section{Conclusion and CDNA resources}

We generated a full-length enriched cDNA library of Thellungiella halophila from various tissues and whole plants treated with salinity, chilling, freezing stresses, or ABA. We isolated about 20000 full-length enriched cDNA clones (RTFL cDNAs) and sequenced them from both ends, and we outlined the features of their predicted functions (coding Thellungiella proteins) by comparing them with those of Arabidopsis. Moreover, the 35171 RTFL cDNA sequences have been deposited in the DDBJ public data center. The number of $T$. halophila ( $T$. salsuginea) ESTs entries was 9388 as of July 2008, which means that our effort has increased the number of ESTs by four times the 
Table 3: Thellungiela genes showing low identity against Arabidopsis genes classified in 'transport' using GO slim ${ }^{\mathrm{a}}$

\begin{tabular}{|c|c|c|c|c|}
\hline Clone name & InterPro ID & Description & AGI code & E value $c$ \\
\hline RTFLOI-07-HI5 & IPR00I807 & Chloride channel, voltage gated & AT5G40890.2 & I.00E-49 \\
\hline RTFLOI-I2-MI9 & IPR000I94 & ATPase, FI/VI/AI complex, alpha/beta subunit, nucleotide-binding & ATIG60I90.I & $6.00 \mathrm{E}-45$ \\
\hline RTFLOI-29-PI7 & IPR000463 & Cytosolic fatty-acid binding & AT2G25590.I & $8.00 \mathrm{E}-45$ \\
\hline RTFLOI-05-OI8 & IPR000803 & Facilitated glucose transporter & AT3G58I30.2 & $5.00 \mathrm{E}-43$ \\
\hline RTFLOI-2I-MI 5 & IPR0036I2 & Plant lipid transfer protein/seed storage/trypsin-alpha amylase inhibitor & AT2G38540.I & $5.00 \mathrm{E}-43$ \\
\hline RTFLOI-24-GI4 & IPR000264 & Serum albumin & AT5G09460.I & $5.00 \mathrm{E}-43$ \\
\hline RTFL0I-49-P05 & IPR0036I2 & Plant lipid transfer protein/seed storage/trypsin-alpha amylase inhibitor & AT2G38540.I & $5.00 \mathrm{E}-43$ \\
\hline RTFLOI-36-E03 & IPR00727I & Nucleotide-sugar transporter & AT5G65000.2 & $3.00 \mathrm{E}-4 \mathrm{I}$ \\
\hline RTFLOI-05-GI4 & IPR00I993 & Mitochondrial substrate carrier & AT5G42। 30.1 & $3.00 \mathrm{E}-38$ \\
\hline RTFLOI-I4-G02 & IPR000I94 & ATPase, FI/VI/AI complex, alpha/beta subunit, nucleotide-binding & ATIG080I0.2 & I.00E-34 \\
\hline RTFLOI-43-C04 & IPR002075 & Nuclear transport factor 2 & ATIG69250.I & $4.00 \mathrm{E}-34$ \\
\hline RTFLOI-2I-H04 & IPR004240 & Nonaspanin (TM9SF) & AT4GI2650.I & $5.00 \mathrm{E}-34$ \\
\hline RTFLOI-I8-DI7 & IPR006455 & Homeobox domain, ZF-HD class & AT5G42780.I & $2.00 \mathrm{E}-31$ \\
\hline RTFL0I-07-P02 & IPR005829 & Sugar transporter superfamily & AT4GI04I0.I & $2.00 \mathrm{E}-30$ \\
\hline RTFLOI-08-J20 & IPR00I757 & ATPase, $\mathrm{P}$-type, $\mathrm{K} / \mathrm{Mg} / \mathrm{Cd} / \mathrm{Cu} / \mathrm{Zn} / \mathrm{Na} / \mathrm{Ca} / \mathrm{Na} / \mathrm{H}$-transporter & AT2G3II50.I & $3.00 \mathrm{E}-28$ \\
\hline RTFLOI-06-N05 & IPR0036I2 & Plant lipid transfer protein/seed storage/trypsin-alpha amylase inhibitor & AT3GI8840.2 & I.00E-27 \\
\hline RTFLOI-40-MI8 & IPR004240 & Nonaspanin (TM9SF) & ATIGI0950.I & I.00E-27 \\
\hline RTFLOI-II-J2I & IPR000I94 & ATPase, FI/VI/AI complex, alpha/beta subunit, nucleotide-binding & AT3G24503.I & $7.00 \mathrm{E}-27$ \\
\hline RTFLOI-39-123 & IPR008389 & ATPase, $\mathrm{V} 0$ complex, subunit $\mathrm{H}$ & AT4G267I0.2 & $2.00 \mathrm{E}-23$ \\
\hline RTFLOI-52-JI4 & IPR000I94 & ATPase, FI/VI/AI complex, alpha/beta subunit, nucleotide-binding & AT3G54760.I & $5.00 \mathrm{E}-21$ \\
\hline RTFL0I-33-PI4 & IPR000568 & ATPase, F0 complex, subunit A & AT4GI3740.I & $6.00 \mathrm{E}-15$ \\
\hline RTFLOI-0I-D06 & IPR000I94 & ATPase, FI/VI/AI complex, alpha/beta subunit, nucleotide-binding & ATIG29760.I & $6.00 \mathrm{E}-15$ \\
\hline RTFLOI-20-A07 & IPR000I94 & ATPase, FI/VI/AI complex, alpha/beta subunit, nucleotide-binding & ATIG29760.I & $6.00 \mathrm{E}-15$ \\
\hline RTFLOI-28-P24 & IPR001622 & Voltage-dependent potassium channel & AT5G55430.I & $3.00 \mathrm{E}-13$ \\
\hline RTFLOI-25-DI2 & IPR000245 & ATPase, V0 complex, proteolipid subunit C, & ATIG75630.I & $7.00 \mathrm{E}-08$ \\
\hline RTFLOI-22-PI2 & IPR000264 & Serum albumin & AT5G09460.I & I.00E-07 \\
\hline RTFL0I-03-P24 & IPR006|2I & Heavy metal transport/detoxification protein & AT5GII890.I & $2.00 \mathrm{E}-06$ \\
\hline RTFLOI-40-P02 & IPR002946 & Intracellular chloride channel & AT5G08450.3 & 3.00E-04 \\
\hline
\end{tabular}


Table 3: Thellungiela genes showing low identity against Arabidopsis genes classified in 'transport' using GO slim ${ }^{\mathrm{a}}$ (Continued)

\begin{tabular}{|c|c|c|c|c|}
\hline RTFL0I-03-G04 & IPR003663 & Sugar transporter & AT5G50540.I & 0.001 \\
\hline RTFL0I-II-N06 & IPR000I09 & TGF-beta receptor, type I/II extracellular region & AT3G55610.1 & 0.019 \\
\hline RTFL0I-I3-J08 & IPR005829 & Sugar transporter superfamily & AT5G49665.I & 0.073 \\
\hline RTFLOI-II-G05 & IPR007II4 & Major facilitator superfamily & ATIG05300.2 & 0.075 \\
\hline RTFLOI-|7-J21 & IPR000I94 & ATPase, FI/VI/AI complex, alpha/beta subunit, nucleotide-binding & AT4G I9830.I & 0.25 \\
\hline RTFL0I-38-L07 & IPROIIIII6 & SecA Wing and Scaffold & AT3G55I60.I & 0.76 \\
\hline RTFLOI-20-G20 & IPR004I00 & ATPase, $\mathrm{FI} / \mathrm{VI} / \mathrm{AI}$ complex, alpha/beta subunit, $\mathrm{N}$-terminal & AT5G60470.I & 1.2 \\
\hline
\end{tabular}

a The 9,569 nonredundant Thellungiella genes were submitted to InterPro. The 763 Thellungiella genes exhibiting low identity (E value $>$ I.0e-50) against Arabidopsis genes assigned to InterPro ID were classified according to the GO terms using GO slim.

b Arabidopsis gene showing the highest identity with the Thellungiella cDNA clone.

c Sequence identity between the Thellungiella clone and the Arabidopsis counterpart (show AGI code) using BLASTX searches

against Arabidopsis database.

number before our study. Our sequences will thus contribute to correct annotation of the Thellungiella genome sequence in the near future. The RTFL cDNA clones will also enable the construction of overexpressing mutant plants by introduction of the cDNAs driven by a constitutive promoter, as well as the complementation of Thellungiella mutants and the determination of promoter regions in the Thellungiella genome. The RTFL clones will be available for distribution through the RIKEN Bioresource Center http://www.brc.riken.go.jp/lab/epd/Eng/.

\section{Methods}

\section{Plant materials and stress treatments}

Thellungiella halophila (Shandong ecotype) seeds were sown on Murashige and Skoog (MS) plates containing $0.8 \%(\mathrm{wt} / \mathrm{vol})$ agar and $1 \%$ sucrose. The seeds were stratified at $4{ }^{\circ} \mathrm{C}$ for two weeks and then transferred to $22^{\circ} \mathrm{C}$ under continuous light for germination and growth. Three weeks after germination, seedlings of Thellungiella were transferred to $250 \mathrm{mM} \mathrm{NaCl}$ (salt stress) or $50 \mu \mathrm{M} \mathrm{ABA}$ (ABA treatment) water, or were transferred onto separate 9 -cm plastic pots filled with a 1:1 mixture of perlite/vermiculite and watered with 1000-fold diluted Hyponex ${ }^{\mathrm{TM}}$ (Hyponex, Osaka, Japan). One week after transfer onto the soil pots under 16 hours light -8 hours darkness at $22^{\circ} \mathrm{C}$, the seedlings were subjected to $4{ }^{\circ} \mathrm{C}$ (cold stress) or $-6^{\circ} \mathrm{C}$ (freezing stress) in a growth chamber under 24 hours darkness.

A Thellungiella full-length cDNA library was constructed from a mixture of mRNA extracted from stress-treated plants and various tissues of Thellungiella. Thellungiella plants were subjected to various stress treatments: highsalinity (250 mM NaCl for 1, 2, 3, 7, and 14 days), cold temperatures $\left(4^{\circ} \mathrm{C}\right.$ for $2,4,8$, and 24 hours), freezing temperatures $\left(-6^{\circ} \mathrm{C}\right.$ for $1,2,4$, or 8 hours $)$, or ABA $(50 \mu \mathrm{M}$ ABA for 1, 2, 4, and 8 hours). Control plants were grown under unstressed conditions under16 hours light -8 hours darkness at $22^{\circ} \mathrm{C}$. After the stress treatments, mRNA was extracted from whole plants (salt stress and ABA treatment) or rosette leaves (cold and freezing stresses) collected at each point in time. Rosette leaves and cauline leaves, roots, flowers, and siliques were collected from 7 to 10 -week-old plants, and mature seeds were collected from 12- to 20-week-old plants.

\section{RNA extraction and construction of a full-length cDNA library}

Total RNA was prepared by using TRIZOL Reagent (Life Technologies, Rockville, MD, USA) from the treated samples. A full-length cDNA library was constructed as previously reported $[14,27,28]$ by means of the biotinylated CAP trapper method using trehalose-thermoactivated reverse transcriptase [28]. We used the $\lambda$ FLCIII [33] vector, which accommodates CDNAs in a broad range of sizes and is thus useful for the high-efficiency cloning of long cDNA fragments, for construction of the cDNA libraries [33]. The $\lambda$ FLCIII vectors can also be bulk-excised by a Cre-loxbased system free of size bias to generate the plasmid libraries. Normalization [29] was also introduced in the construction of the full-length cDNA library to reduce the frequency of highly expressed mRNAs in the library. The method is based on hybridization of first-strand, fulllength cDNA as the tester and cellular biotinylated RNA extracted from stress-treated plants and various tissues of Thellungiella as the normalizing driver.

\section{Sequencing of Thellungiella cDNA clones}

The DNA of each clone was directly amplified from 384 bacterial cultures in a glycerol stock plate by the RCA 
method [55] using a TempliPhi HT DNA amplification kit (GE Healthcare, United Kingdom). End sequencing of 20000 clones was performed using ABI 3700 capillary sequencers (Applied Biosystems, Foster City, CA, U.S.). The M13 (-21) primer (5'-TGTAAAACGACGGCCAGT-3') and the 1233 primer (5'-AGCGGATAACAATTTCACACAGGA-3') were used for forward and reverse sequencing, respectively.

\section{Trimming of sequence data and assembly}

We used $\operatorname{sim} 4$ software for the detection of vector sequences [56]. Raw sequence data were base-called using the Phred software $[57,58]$. Regions of low quality found at both edges of each raw sequence were discarded, and we extracted only the high-quality region (Phred quality score $>14$, and more than 20 bases repeated). After this initial evaluation, sequence data shorter than 100 bases in length or with many low-quality regions (Phred quality score $\leq 14$, and more than $50 \%$ of its total length) were omitted. The ESTs were assembled by using CAP3 software [35] with its default parameters. All sequences were submitted to the DNA Databank of Japan (DDBJ) with accession numbers $\underline{B Y 800476}$ to BY835646.

\section{cDNA insert size of the RTFL clones}

The sequence lengths of the Thellungiella cDNA inserts were determined from a total of 1,161 clones by digestion with SfiI (in the cDNA cloning site) or PCR amplification using T3 (5'-TGTAAAACGACGGCCAGT-3') and T7 primers (5'-AATACGACTCACTATAGGG-3').

\section{Full-length cDNA library quality}

To examine the proportion of full-length cDNA clones in this library, we selected the following clones as calculation objects: (1) clones with sequences from both ends, and (2) clones showing an Expected Value of $(E)<1.0 e^{-20}$ in a fastx search using forward sequences as queries against Arabidopsis proteins (TIGR v5, ATH1.pep), with the correct direction of the reading frame. We used the following criteria to classify clones as full-length: (1) clones must include the first methionine, and (2) the reverse reading sequence must include the polyA sequence.

\section{Scaffold construction}

In order to obtain a non-redundant set of transcripts, the clones were clustered according to clone names. To accomplish this, we parsed the ace file from the CAP3 program output to build scaffolds, which are groups of sequences that represent a unique transcript for which the relative position and orientation of the fragments can be inferred. Using clone names, the contigs or singletons corresponding to the two ends of a given clone were joined by adding $20 \mathrm{~N}$ 's in the middle of both sequences. Since 20 is more than the default window size in BLAST searches, these N's did not interfere with the BLAST analyses.

\section{Functional annotation of the sequences}

Once these scaffolds were created, the sequences were submitted to InterPro [36] to obtain functional domain information. Protein matches in InterPro were pre-calculated with InterProScan software, available from http:// www.ebi.ac.uk/Tools/InterProScan/[37,59]. InterProScan provided the corresponding InterPro accession numbers and GO annotation in the results [37]. The genes assigned to InterPro ID were classified according to the GO terms developed by InterPro using Plant GO Slim (http://www.geneontology.org/GO.slims.shtml; [38]).

\section{Authors' contributions}

TT contributed to and participated in the entire study and drafted the manuscript. TS, KM, AI, and AK performed the bioinformatics analyses (assembly, clustering, annotation and comparative analysis). YT carried out annotation and registration in DDBJ. AT and YS conducted sequencing of the cDNA clones. MS assisted in the construction of the cDNA library. HO checked the length distribution of the cDNA inserts. YS and ST helped draft the manuscript. KS coordinated the project and helped draft the manuscript.

\section{Additional material}

\section{Additional file 1}

List of 9,569 culusters with accession numbers and the annotation. Click here for file

[http://www.biomedcentral.com/content/supplementary/14712229-8-115-S1.xls]

\section{Additional file 2}

Thellungiela genes showing low identity against Arabidopsis genes classified in 'transport' using GO slim with the most homologous gene. Click here for file

[http://www.biomedcentral.com/content/supplementary/14712229-8-115-S2.xls]

\section{Acknowledgements}

We thank the technical staff of the Sequencing Technology Team and Genome Annotation and Comparative Analysis Team at the RIKEN Genomic Sciences Center and Integrated Genome Informatics Research Unit and the Plant Genomic Network Research Team at the RIKEN Plant Science Center for their technical assistance. We also thank Tadashi Negishi and Miho Nagumo of the Faculty of Applied Bioscience, Tokyo University of Agriculture, for their technical assistance. This work was supported by the RIKEN Plant Science Center; by a Grant-in-aid for Young Scientists from the Ministry of Education, Culture, Sports, Science, and Technology of Japan (TT); and by the Science Research Promotion Fund (2007) from the Promotion and Mutual Aid Corporation for Private Schools of Japan.

\section{References}

I. Bressan RA, Zhang C, Zhang H, Hasegawa PM, Bohnert HJ, Zhu JK: Learning from the Arabidopsis experience. The next gene search paradigm. Plant Physiol 200I, I 27(4): I354-I360.

2. Gong Q, Li P, Ma S, Indu Rupassara S, Bohnert HJ: Salinity stress adaptation competence in the extremophile Thellungiella 
halophila in comparison with its relative Arabidopsis thaliana. Plant J 2005, 44(5):826-839.

3. Inan G, Zhang Q, Li P, Wang Z, Cao Z, Zhang H, Zhang C, Quist TM, Goodwin SM, Zhu J, et al:: Salt cress. A halophyte and cryophyte Arabidopsis relative model system and its applicability to molecular genetic analyses of growth and development of extremophiles. Plant Physiol 2004, I 35(3): I7| 8-1737.

4. Li P, Mane SP, Sioson AA, Robinet CV, Heath LS, Bohnert HJ, Grene $R$ : Effects of chronic ozone exposure on gene expression in Arabidopsis thaliana ecotypes and in Thellungiella halophila. Plant Cell Environ 2006, 29(5):854-868.

5. Taji T, Seki M, Satou M, Sakurai T, Kobayashi M, Ishiyama K, Narusaka Y, Narusaka M, Zhu JK, Shinozaki K: Comparative genomics in salt tolerance between Arabidopsis and Arabidopsis-related halophyte salt cress using Arabidopsis microarray. Plant Physiol 2004, I35(3): 1697-1709.

6. Vera-Estrella R, Barkla BJ, Garcia-Ramirez L, Pantoja O: Salt stress in Thellungiella halophila activates $\mathrm{Na}+$ transport mechanisms required for salinity tolerance. Plant Physiol 2005, 139(3): 1507-1517.

7. Volkov $V$, Amtmann A: Thellungiella halophila, a salt-tolerant relative of Arabidopsis thaliana, has specific root ion-channel features supporting $\mathrm{K}+/ \mathrm{Na}+$ homeostasis under salinity stress. Plant J 2006, 48(3):342-353.

8. Wong CE, Li Y, Labbe A, Guevara D, Nuin P, Whitty B, Diaz C, Golding GB, Gray GR, Weretilnyk EA, et al.: Transcriptional profiling implicates novel interactions between abiotic stress and hormonal responses in Thellungiella, a close relative of Arabidopsis. Plant Physiol 2006, I 40(4): I 437-I 450.

9. Wong CE, Li Y, Whitty BR, Diaz-Camino C, Akhter SR, Brandle JE, Golding GB, Weretilnyk EA, Moffatt BA, Griffith M: Expressed sequence tags from the Yukon ecotype of Thellungiella reveal that gene expression in response to cold, drought and salinity shows little overlap. Plant Mol Biol 2005, 58(4):56I-574

10. Alexandrov NN, Troukhan ME, Brover VV, Tatarinova T, Flavell RB, Feldmann KA: Features of Arabidopsis genes and genome discovered using full-length cDNAs. Plant Mol Biol 2006, 60(I):69-85

II. Zhu JK: Plant salt tolerance. Trends Plant Sci 200I, 6(2):66-7I.

12. Seki M, Satou M, Sakurai T, Akiyama K, lida K, Ishida J, Nakajima M, Enju A, Narusaka M, Fujita M, et al.: RIKEN Arabidopsis full-length (RAFL) CDNA and its applications for expression profiling under abiotic stress conditions. J Exp Bot 2004, 55(395):213-223

13. Seki M, Carninci P, Nishiyama Y, Hayashizaki Y, Shinozaki K: Highefficiency cloning of Arabidopsis full-length cDNA by biotinylated CAP trapper. Plant J 1998, I5(5):707-720.

14. Seki M, Narusaka M, Kamiya A, Ishida J, Satou M, Sakurai T, Nakajima M, Enju A, Akiyama K, Oono Y, et al.: Functional annotation of a full-length Arabidopsis cDNA collection. Science 2002, 296(5565): $|4|-\mid 45$

15. Kikuchi S, Satoh K, Nagata T, Kawagashira N, Doi K, Kishimoto N, Yazaki J, Ishikawa M, Yamada $\mathrm{H}$, Ooka $\mathrm{H}$, et al.: Collection, mapping, and annotation of over 28,000 cDNA clones from japonica rice. Science 2003, 30 I (563 I):376-379.

16. Nanjo T, Futamura N, Nishiguchi M, Igasaki T, Shinozaki K, Shinohara $\mathrm{K}$ : Characterization of full-length enriched expressed sequence tags of stress-treated poplar leaves. Plant Cell Physiol 2004, 45( I 2): 1 738- 7748.

17. Nanjo T, Sakurai T, Totoki Y, Toyoda A, Nishiguchi M, Kado T, Igasaki T, Futamura N, Seki M, Sakaki Y, et al.: Functional annotation of 19,84 I Populus nigra full-length enriched cDNA clones. $B M C$ Genomics 2007, 8:448.

18. Ogihara Y, Mochida K, Kawaura K, Murai K, Seki M, Kamiya A, Shinozaki K, Carninci P, Hayashizaki Y, Shin IT, et al.: Construction of a full-length cDNA library from young spikelets of hexaploid wheat and its characterization by large-scale sequencing of expressed sequence tags. Genes Genet Syst 2004, 79(4):227-232.

19. Jia J, Fu J, Zheng J, Zhou X, Huai J, Wang J, Wang M, Zhang Y, Chen $X$, Zhang J, et al:: Annotation and expression profile analysis of 2073 full-length cDNAs from stress-induced maize (Zea mays L.) seedlings. Plant J 2006, 48(5):71 0-727.

20. Ota T, Suzuki $Y$, Nishikawa T, Otsuki T, Sugiyama T, Irie R, Wakamatsu A, Hayashi K, Sato H, Nagai K, et al.: Complete sequencing and characterization of 21,243 full-length human cDNAs. Nat Genet 2004, 36(I):40-45.
21. Carninci P, Waki K, Shiraki T, Konno H, Shibata K, Itoh M, Aizawa K, Arakawa $T$, Ishii $Y$, Sasaki D, et al.: Targeting a complex transcriptome: the construction of the mouse full-length cDNA encyclopedia. Genome Res 2003, I3(6B): | 273-I289.

22. Kawai J, Shinagawa A, Shibata K, Yoshino M, Itoh M, Ishii Y, Arakawa $\mathrm{T}$, Hara A, Fukunishi $\mathrm{Y}$, Konno $\mathrm{H}$, et al:: Functional annotation of a full-length mouse cDNA collection. Nature 200I, 409(682I):685-690.

23. Rubin GM, Hong L, Brokstein P, Evans-Holm M, Frise E, Stapleton M, Harvey DA: A Drosophila complementary DNA resource. Science 2000, 287(546I):2222-2224.

24. Stapleton M, Carlson J, Brokstein P, Yu C, Champe M, George R, Guarin H, Kronmiller B, Pacleb J, Park S, et al.: A Drosophila fulllength cDNA resource. Genome Biol 2002, 3(I 2): RESEARCH0080.

25. Stapleton M, Liao G, Brokstein P, Hong L, Carninci P, Shiraki T, Hayashizaki Y, Champe M, Pacleb J, Wan K, et al:: The Drosophila gene collection: identification of putative full-length cDNAs for $70 \%$ of D. melanogaster genes. Genome Res 2002, I 2(8): | 294-| 300

26. Seki M, Narusaka M, Ishida J, Nanjo T, Fujita M, Oono Y, Kamiya A, Nakajima M, Enju A, Sakurai T, et al.: Monitoring the expression profiles of 7000 Arabidopsis genes under drought, cold and high-salinity stresses using a full-length cDNA microarray. Plant J 2002, 3 I (3):279-292.

27. Carninci P, Kvam C, Kitamura A, Ohsumi T, Okazaki Y, Itoh M, Kamiya M, Shibata K, Sasaki N, Izawa M, et al.: High-efficiency fulllength cDNA cloning by biotinylated CAP trapper. Genomics 1996, 37(3):327-336.

28. Carninci P, Nishiyama Y, Westover A, Itoh M, Nagaoka S, Sasaki N, Okazaki Y, Muramatsu M, Hayashizaki Y: Thermostabilization and thermoactivation of thermolabile enzymes by trehalose and its application for the synthesis of full length cDNA. Proc Natl Acad Sci USA 1998, 95(2):520-524.

29. Carninci P, Shibata Y, Hayatsu N, Sugahara Y, Shibata K, Itoh M, Konno H, Okazaki Y, Muramatsu M, Hayashizaki Y: Normalization and subtraction of cap-trapper-selected cDNAs to prepare full-length cDNA libraries for rapid discovery of new genes. Genome Res 2000, 10(10):1617-1630.

30. Carninci P, Westover A, Nishiyama Y, Ohsumi T, Itoh M, Nagaoka S, Sasaki N, Okazaki Y, Muramatsu M, Schneider C, et al:: High efficiency selection of full-length cDNA by improved biotinylated cap trapper. DNA Res I997, 4(I):6I-66.

31. Ichikawa T, Nakazawa M, Kawashima M, lizumi H, Kuroda $H$, Kondou Y, Tsuhara Y, Suzuki K, Ishikawa A, Seki M, et al.: The FOX hunting system: an alternative gain-of-function gene hunting technique. Plant J 2006, 48(6): 974-985.

32. Nishiyama T, Fujita T, Shin IT, Seki M, Nishide H, Uchiyama I, Kamiya A, Carninci P, Hayashizaki Y, Shinozaki K, et al:: Comparative genomics of Physcomitrella patens gametophytic transcriptome and Arabidopsis thaliana: implication for land plant evolution. Proc Natl Acad Sci USA 2003, I 00( I 3):8007-80I2.

33. Carninci P, Shibata Y, Hayatsu N, Itoh M, Shiraki T, Hirozane T, Watahiki A, Shibata K, Konno H, Muramatsu M, et al.: Balanced-size and long-size cloning of full-length, cap-trapped cDNAs into vectors of the novel lambda-FLC family allows enhanced gene discovery rate and functional analysis. Genomics 200I, 77(I2):79-90.

34. Sakurai T, Satou M, Akiyama K, lida K, Seki M, Kuromori T, Ito T, Konagaya A, Toyoda T, Shinozaki K: RARGE: a large-scale database of RIKEN Arabidopsis resources ranging from transcriptome to phenome. Nucleic Acids Res 2005:D647-650.

35. Huang $X$, Madan A: CAP3: A DNA sequence assembly program. Genome Res 1999, 9(9):868-877.

36. Zdobnov EM, Apweiler R: InterProScan - an integration platform for the signature-recognition methods in InterPro. Bioinformatics 200I, 17(9):847-848.

37. Mulder NJ, Apweiler R, Attwood TK, Bairoch A, Bateman A, Binns D, Bork P, Buillard V, Cerutti L, Copley R, et al.: New developments in the InterPro database. Nucleic Acids Res 2007:D224-228.

38. Ashburner M, Ball CA, Blake JA, Botstein D, Butler H, Cherry JM, Davis AP, Dolinski K, Dwight SS, Eppig JT, et al.: Gene ontology: tool for the unification of biology. The Gene Ontology Consortium. Nat Genet 2000, 25(I):25-29

39. Zhu JK: Genetic analysis of plant salt tolerance using Arabidopsis. Plant Physiol 2000, 124(3):94I-948. 
40. Apse MP, Sottosanto JB, Blumwald E: Vacuolar cation/H+ exchange, ion homeostasis, and leaf development are altered in a T-DNA insertional mutant of AtNHXI, the Arabidopsis vacuolar $\mathbf{N a}+/ \mathbf{H}+$ antiporter. Plant J 2003, 36(2):229-239.

4I. Shi H, Ishitani M, Kim C, Zhu JK: The Arabidopsis thaliana salt tolerance gene SOSI encodes a putative $\mathbf{N a}+/ \mathrm{H}+$ antiporter. Proc Natl Acad Sci USA 2000, 97( 12 2):6896-690I.

42. Sunarpi, Horie T, Motoda J, Kubo M, Yang H, Yoda K, Horie R, Chan WY, Leung HY, Hattori K, et al:: Enhanced salt tolerance mediated by AtHKTI transporter-induced $\mathrm{Na}$ unloading from xylem vessels to xylem parenchyma cells. Plant J 2005, 44(6):928-938.

43. Apse MP, Aharon GS, Snedden WA, Blumwald E: Salt tolerance conferred by overexpression of a vacuolar $\mathrm{Na}+/ \mathrm{H}+$ antiport in Arabidopsis. Science 1999, 285(543 I): I256-1258.

44. Shi $H$, Lee BH, Wu SJ, Zhu JK: Overexpression of a plasma membrane $\mathbf{N a}+/ \mathrm{H}+$ antiporter gene improves salt tolerance in Arabidopsis thaliana. Nat Biotechnol 2003, 2I(I):8I-85.

45. Kant $S$, Kant $P$, Raveh E, Barak S: Evidence that differential gene expression between the halophyte, Thellungiella halophila, and Arabidopsis thaliana is responsible for higher levels of the compatible osmolyte proline and tight control of $\mathrm{Na}+$ uptake in T. halophila. Plant Cell Environ 2006, 29(7): I220-I 234.

46. Chen TY: Structure and function of clc channels. Annu Rev Physiol 2005, 67:809-839.

47. Hechenberger M, Schwappach B, Fischer WN, Frommer WB, Jentsch T], Steinmeyer K: A family of putative chloride channels from Arabidopsis and functional complementation of a yeast strain with a CLC gene disruption. I Biol Chem 1996, 27I(52):33632-33638.

48. Li WY, Wong FL, Tsai SN, Phang TH, Shao G, Lam HM: Tonoplastlocated GmCLCI and GmNHXI from soybean enhance $\mathrm{NaCl}$ tolerance in transgenic bright yellow (BY)-2 cells. Plant Cell Environ 2006, 29(6): I I 22-I I 37.

49. Vitart V, Baxter I, Doerner P, Harper JF: Evidence for a role in growth and salt resistance of a plasma membrane $\mathrm{H}^{+}$ ATPase in the root endodermis. Plant J 200I, 27(3): $191-201$.

50. Popova L, Balnokin Y, Dietz KJ, Gimmler H: Na+-ATPase from the plasma membrane of the marine alga Tetraselmis (Platymonas) viridis forms a phosphorylated intermediate. FEBS Lett 1998, 426(2): 161-164.

5I. Wiangnon K, Raksajit W, Incharoensakdi A: Presence of a Na+stimulated P-type ATPase in the plasma membrane of the alkaliphilic halotolerant cyanobacterium Aphanothece halophytica. FEMS Microbiol Lett 2007, 270(1):139- 145.

52. Waditee R, Hibino T, Tanaka $Y$, Nakamura $T$, Incharoensakdi $A$, Takabe T: Halotolerant cyanobacterium Aphanothece halophytica contains an $\mathrm{Na}(+) / \mathrm{H}(+)$ antiporter, homologous to eukaryotic ones, with novel ion specificity affected by C-terminal tail. J Biol Chem 200I, 276(40):3693I-36938.

53. Kirsch M, An Z, Viereck R, Low R, Rausch T: Salt stress induces an increased expression of $\mathrm{V}$-type $\mathrm{H}(+)$-ATPase in mature sugar beet leaves. Plant Mol Biol 1996, 32(3):543-547.

54. Batelli G, Verslues PE, Agius F, Qiu Q, Fujii H, Pan S, Schumaker KS, Grillo S, Zhu JK: SOS2 promotes salt tolerance in part by interacting with the vacuolar H+-ATPase and upregulating its transport activity. Mol Cell Biol 2007, 27(22):778I-7790.

55. Dean FB, Nelson JR, Giesler TL, Lasken RS: Rapid amplification of plasmid and phage DNA using Phi 29 DNA polymerase and multiply-primed rolling circle amplification. Genome Res 200I, I I(6): 1095-1099.

56. Florea L, Hartzell G, Zhang Z, Rubin GM, Miller W: A computer program for aligning a cDNA sequence with a genomic DNA sequence. Genome Res 1998, 8(9):967-974.

57. Ewing B, Green P: Base-calling of automated sequencer traces using phred. II. Error probabilities. Genome Res 1998 8(3): $186-194$.

58. Ewing B, Hillier L, WendI MC, Green P: Base-calling of automated sequencer traces using phred. I. Accuracy assessment. Genome Res 1998, 8(3): 175-185.

59. Petryszak R, Kretschmann E, Wieser D, Apweiler R: The predictive power of the CluSTr database. Bioinformatics 2005 2I(I8):3604-3609.

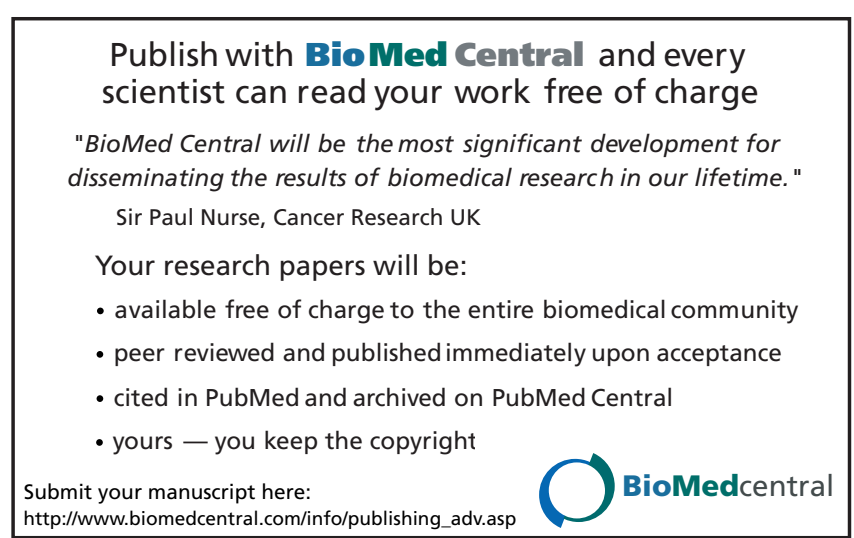

